See Article page 127.

\section{Commentary: Pulmonary valve replacement through a small incision is attractive but means limited possibilities for right ventricular outflow tract repair}

\author{
Thierry Carrel, MD
}

Repair or replacement of the pulmonary valve is a less common surgical treatment of the heart valves in adults (compared with the need for aortic, mitral, and tricuspid valve operations), but in those suffering from congenital heart diseases, pulmonary valve replacement (PVR) is one of the most common procedures. An increasing number of patients with tetralogy of Fallot and other RVOT pathologies require one or multiple reinterventions in the midto long-term follow-up after primary repair, mainly because of pulmonary valve regurgitation.

Until recently, the standard method was the surgical insertion of a tissue valve, but new approaches for less invasive replacement of the pulmonary valve have been increasingly explored in the last 10 to 15 years. In 2006, Berdat and Carrol $^{1}$ published a short article summarizing our preliminary experience with a hybrid technique of "less invasive PVR" with an injectable catheter-based valved stent introduced through the right ventricular outflow tract (RVOT) or through the right ventricle into the beating heart and transmurally fixed to prevent dislocation. This method received little attention at the time, but years later Suleiman and colleagues ${ }^{2}$ reported a larger series using the same device.

As for the treatment of aortic valves, catheter-based interventions have emerged as an attractive alternative to

From the Department of Cardiovascular Surgery, University Hospital and University of Bern, Bern, Switzerland.

Disclosures: Dr Carrel serves on the advisory board of Xeltis, Inc.

The Journal policy requires editors and reviewers to disclose conflicts of interest and to decline handling or reviewing manuscripts for which they may have a conflict of interest. The editors and reviewers of this article have no conflicts of interest.

Received for publication Dec 27, 2020; revisions received Dec 27, 2020; accepted for publication Dec 29, 2020; available ahead of print Dec 30, 2020.

Address for reprints: Thierry Carrel, MD, Department of Cardiac Surgery, University Hospital, Rämistrasse 100, CH-8091 Zürich, Switzerland (E-mail: thierry.carrel@ gmail.com).

JTCVS Techniques 2021;6:132-3

2666-2507

Copyright $@ 2021$ The Authors. Published by Elsevier Inc. on behalf of The American Association for Thoracic Surgery. This is an open access article under the CC BY-NCND license (http://creativecommons.org/licenses/by-nc-nd/4.0/).

https://doi.org/10.1016/j.xjtc.2020.12.037

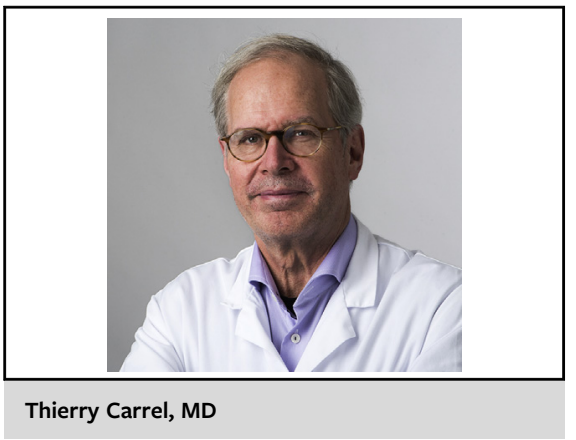

CENTRAL MESSAGE

Pulmonary valve replacement

through a left anterior mini-

thoracotomy is attractive for

redo in grown-up congenital

heart disease patients, but

limited exposure precludes more

complex RVOT reconstruction.

surgery in this particular population, with an increasing number performed over the last decade. ${ }^{3}$ However, this technique may be limited by patient size (ie, small children) or by the anatomy of the RVOT and the size of the pulmonary annulus and the main pulmonary artery, which are often excessively dilated. Nevertheless, catheter-based PVR has revolutionized the care of these patients, particularly in those with pulmonary valve regurgitation or stenosis (much less frequent) following tetralogy of Fallot repair and in those with other underlying diagnoses, including truncus arteriosus, pulmonary stenosis, or atresia who had received a surgically implanted pulmonary valve, such as a homograft or a "classical" tissue valve, that shows structural degeneration. In addition, after the pulmonary autograft (Ross) procedure, patients may present with a hemodynamically significant problem of a neo-pulmonary valve. ${ }^{4}$

For all these patients, minimizing procedural invasiveness and risks is mandatory. The report by $\mathrm{Said}^{5}$ in this issue of the Journal is timely, but the experience with PVR through a small left-sided anterior thoracotomy remains limited. Although the concept is attractive, there are some major drawbacks: the procedure needs peripheral cannulation for cardiopulmonary bypass, and concomitant extended procedures (ie, to close a residual ventricular septal defect, to resect hypertrophic muscle in the RVOT, or to enlarge the main branches of the pulmonary artery) 
might not be as easy (or even not possible) as when performed through a standard approach.

For this reason, the exact morphology of the RVOT and pulmonary artery must be studied carefully preoperatively by transthoracic echocardiography and magnetic resonance imaging to determine the extent of the reconstruction, as well as the potential size of the prosthetic valve.

Said provides a nice short description of PVR through a left anterior mini-thoracotomy with a corresponding video. In these patients, optimal management of venous return is of paramount importance to obtain a clear view in a bloodless field through the mini-incision. Although the approach described by Said and previously by Nellis and coauthors ${ }^{6}$ seems attractive for a well-defined group of patients, additional experience is needed before it can be applied in those with a previous conduit in place or more complex RVOT anatomy that requires more corrections than a simple PVR.

In addition, it is unclear whether this approach allows the insertion of a really oversized tissue valve (relative to the native size of the pulmonary annulus) following an adequate transannular patch enlargement of the RVOT to prophylactically address the classical mismatch between patient growth and the "fixed" size of the pulmonary valve.

\section{References}

1. Berdat PA, Carrel T. Off-pump pulmonary valve replacement with the new Shelhigh injectable stented pulmonic valve. J Thorac Cardiovasc Surg. 2006;131: 1192-3.

2. Suleiman T, Kavinsky CJ, Skerritt C, Kenny D, Ilbawi MN, Caputo M. Recent development in pulmonary valve replacement after tetralogy of Fallot repair: the emergence of hybrid approaches. Front Surg. 2015;2:22.

3. Momenah TS, El Oakley R, Al Najashi K, Khoshhal S, Al Qethamy H, Bonhoeffer P. Extend application of percutaneous pulmonary valve implantation. J Am Coll Cardiol. 2009;53:1859-63.

4. Pretorius V, Jones A, Taylor D, Coe Y, Ross DB. Percutaneous valved stent repair of a failed homograft: implications for the Ross procedure. Can J Cardiol. 2008;8: e54-5.

5. Said SM. Minimally invasive pulmonary valve replacement via left anterior minithoracotomy. J Thorac Cardiovasc Surg Tech. 2021;6:127-9.

6. Nellis JR, Vekstein AM, Meza JM, Andersen ND, Haney JC, Turek JW. Left anterior mini-incision for pulmonary valve replacement following tetralogy of Fallot repair. Innovations (Phila). 2020;2:106-10. 